\title{
Assessment of mucociliary clearance as an indicator of nasal function in patients with COVID-19: a cross-sectional study
}

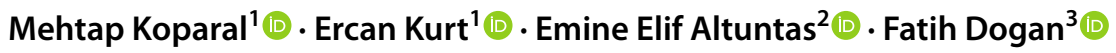

Received: 27 August 2020 / Accepted: 23 October 2020 / Published online: 13 November 2020

c) Springer-Verlag GmbH Germany, part of Springer Nature 2020

\begin{abstract}
Purpose We assessed the effects of COVID-19 infection on nasal mucociliary activity.

Methods The study was conducted in the pandemic wards of Adiyaman University Training and Research Hospital during April and May 2020. All patients admitted to the COVID-19 pandemic wards during the study period were invited to participate in the study. The study included 40 adults who agreed to participate and underwent a mucociliary clearance test successfully. The primary outcome was mucociliary clearance time and the secondary variables of interest were age, sex, and sino-nasal outcome test- 22 scores. The control group included 40 concomitant healthy patients who visited the outpatient ear, nose and throat clinic with non-nasal symptoms.

Results The study included 40 COVID-19-positive patients and 40 healthy controls. The mean mucociliary clearance times of the study $(15.53 \pm 5.57 \mathrm{~min})$ and control $(9.50 \pm 3.70 \mathrm{~min})$ groups were significantly different $(Z=4.675, p<0.001)$. However, the mucociliary clearance time was not significantly different between males and females $(t=0.590, p=0.558)$. Conclusions Nasal mucociliary clearance time was prolonged in COVID-19 patients compared to healthy controls. Thus, we conclude that smell and taste are crucial symptoms that should not be overlooked in patients suspected of COVID-19 disease.
\end{abstract}

Keywords COVID-19 $\cdot$ Mucociliary clearance $\cdot$ Nasal disorders $\cdot$ Smell disorders

\section{Introduction}

The coronavirus disease 2019 (COVID-19) pandemic is the most serious global health crisis since the Spanish flu outbreak of 1917. The first COVID-19 case was reported in Wuhan province in China in December 2019 [1]. Due to the availability of public transport systems and high international mobility, the disease has spread rapidly throughout Europe and the United States. Recent figures published by the World Health Organization indicate that the virus has caused over 4.82 million cases and resulted in 316,959 deaths [2].

Mehtap Koparal

drmehtapkoparal@gmail.com

1 Department of Otolaryngology, Adiyaman University Education and Training Hospital, Adiyaman, Turkey

2 Department of Otolaryngology, Faculty of Medicine, Cumhuriyet University, Sivas, Turkey

3 Department of Plastic, Reconstructive and Aesthetic Surgery, Adiyaman University Education and Training Hospital, Adıyaman, Turkey
COVID-19 causes mild to severe acute respiratory syndrome (SARS) and is caused by SARS coronavirus- 2 (SARS-CoV-2). The clinical manifestations of COVID-19 include fever, dry cough, fatigue, sputum production, shortness of breath, sore throat and headache. Anecdotal reports suggest that losses of smell and taste are potential early symptoms or subclinical markers of COVID-19 infection; a preliminary study from Iran found a significant increase in new-onset anosmia in patients with COVID-19 [3].

An Italian study found that $33 \%$ of 59 patients hospitalised with COVID-19 reported a chemosensory disorder [3]. However, it is unclear whether these findings are unique to COVID-19 infections requiring hospitalisation, are causally related to COVID-19 disease or merely due to increased recognition of post-viral anosmia. Insight into the timing and association of loss of smell or taste with COVID-19 is crucial because patients with acute anosmia may be asymptomatic carriers of the infection and unwittingly facilitate the spread of the disease [3].

Nasal mucociliary clearance is the primary defence mechanism of the respiratory system [4]. The mucous membrane starts in the nose and extends to the upper and lower airways 
[5]. Inhaled particles adhere to the nasal mucosa, which lines the nasal cavity in a single a layer [6], and efficient and coordinated ciliary activity transports the mucus towards the oropharynx. In this way, mucociliary clearance protects the respiratory system against inhaled particles and microorganisms. Ineffective ciliary activity can lead to acute or chronic infections in the upper and lower respiratory tract [5].

Both acute and chronic respiratory infections can disrupt mucociliary function. Because COVID-19 is an acute respiratory condition, we hypothesised that the infection would affect nasal function. Because nasal mucociliary activity is a good predictor of mucosal function, we used it as an indicator of nasal function.

\section{Materials and methods}

\section{Ethics approval}

Our cross-sectional study protocol was approved by the ethics committee of Adiyaman University (Decision date: 18/05/2020, IRB number: 2020/5-38). All participants provided written informed consent before participating in the study.

\section{Study design and sample-size calculation}

The study was conducted in the pandemic wards of Adiyaman University Training and Research Hospital during April and May 2020. The research hospital established six inpatient COVID-19 pandemic wards in March 2020 with a capacity of 112 beds.

A post hoc sample-size calculation was performed based on the primary outcome measure, mucociliary clearance. A total sample size of 76 patients ( 38 study +38 controls) was required to ensure a power of $80 \%$ to compare mean mucociliary clearance differences between two independent groups with an effect size of 0.65 and an alpha error of $5 \%$ (two tailed) [7]. All of the patients in the pandemic wards were assessed by the same physician, and the mucociliary clearance assessment was performed by the same researcher. All patients hospitalised during the study period were invited to participate in the study without sampling.

\section{Participants}

In Turkey, real-time polymerase chain reaction is used to diagnosis COVID-19. All patients admitted to the COVID19 pandemic wards were invited to participate in the study. Of those, 40 adults who agreed to participate and underwent a mucociliary clearance test were included in the study group. The exclusion criteria included smell or taste disorders and positive nasal endoscopic findings on ear, nose and throat (ENT) examination. The control group included 40 concomitant healthy ENT outpatients with non-nasal symptoms (Fig. 1). All patients underwent an ENT examination, including nasal endoscopy using a 0-degree, 4-mm Hopkins nasal endoscope (Karl Storz, Tuttlingen, Germany). The colour of the nasal mucosa (pale-hyperaemic), turbinate hypertrophy, runny nose, septum deviation and polyps were assessed on ENT examination.

\section{Primary and secondary outcome variables}

The primary outcome variable was mucociliary clearance. The secondary variables of interest were age, sex, and sinonasal outcome test-22 (SNOT-22) scores [8].

\section{Data sources/measurements}

Participants were asked to complete a detailed questionnaire that contained such items as systemic disease, previous ENT surgery, family and self-smoking to assess their symptoms. The patients in the study group were asked to complete the

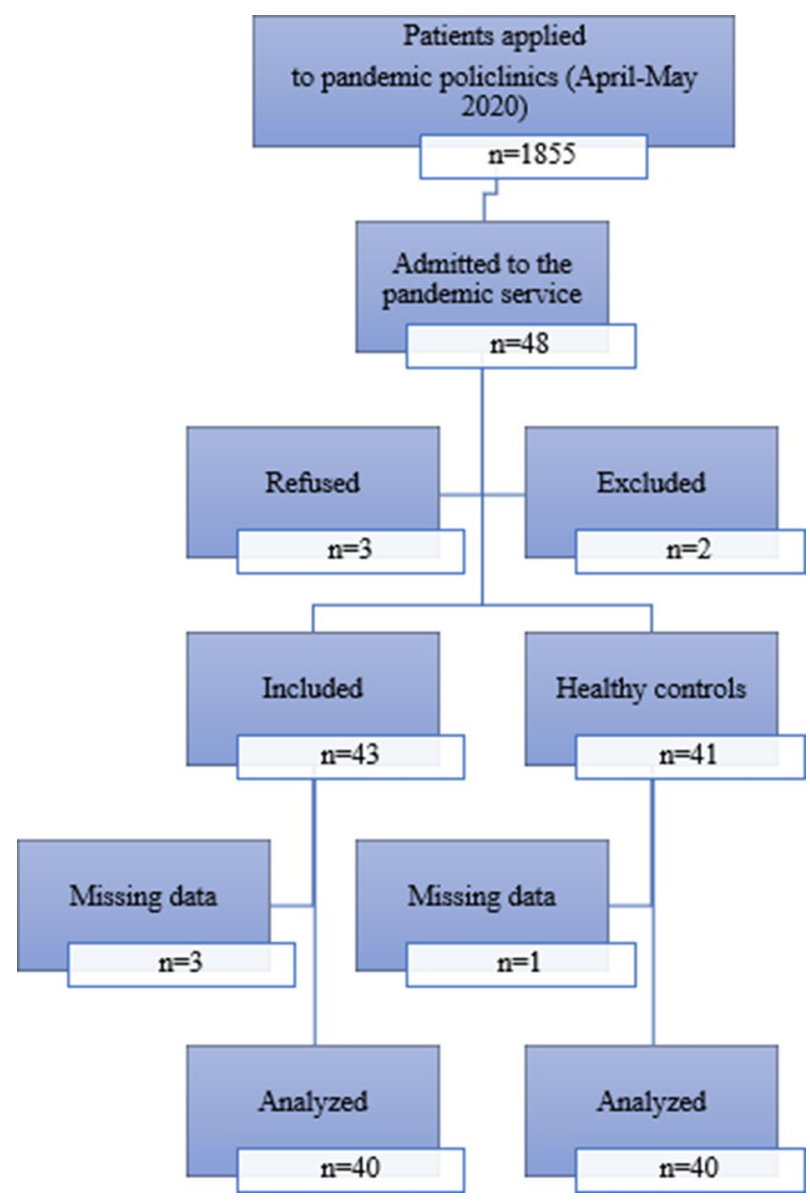

Fig. 1 Patient flowchart according to the Consolidated Standards of Reporting Trials statement 
SNOT-22 questionnaire, which reflects nasal congestion, runny nose, sneezing, nasal discharge, cough, decreased sense of smell, solid nasal discharge, ear fullness, dizziness, ear pain, facial pain, difficulty falling asleep, waking up at night, lack of good night's sleep, waking up tired, fatigue, reduced productivity, reduced concentration, sadness and irritability.

Although several techniques have been used to assess nasal mucociliary clearance, the saccharin test is widely used because it is inexpensive, easy to perform and reliable [9]. The saccharin test was performed on all subjects according to the method described by Greenstone and Cole [10]. The results are expressed as nasal mucociliary clearance time (NMCT), which reflects the efficiency of mucociliary clearance. A normal NMCT is $20-60 \mathrm{~min}$ [10]. A normal saccharin clearance time is $7-15 \mathrm{~min}$ and a clearance time greater than $20 \mathrm{~min}$ indicates pathological mucociliary clearance.

\section{Quantitative variables}

The severity of symptoms was assessed using the SNOT-22 test, which is a modification of the SNOT-20 questionnaire. The test includes symptoms such as nasal obstruction and loss of smell and taste. The SNOT-22 has gained popularity in a short time and is widely used to follow-up conditions like septoplasty, hereditary haemorrhagic telangiectasia and Wegener's granulomatosis, but not chronic rhinosinusitis [11]. Hanci et al. [8] translated the SNOT-22 into Turkish and performed the cross-cultural adaptation and validation in 2015. Details of the questionnaire were explained to all participants by the same researcher (MK).

The SNOT-22 items are scored on a six-point Likert scale where $0=$ "no problem", $1=$ "very mild problem", $2=$ "mild or slight problem", $3=$ "moderate problem", $4=$ "severe problem" and $5=$ "problem as bad as it can be". The total score ranges from $0-110$ with low scores indicating a better quality of life.

A saccharin test was performed to measure mucociliary clearance time. Measurements were made in a room maintained between 20 and $23{ }^{\circ} \mathrm{C}$ with a relative humidity of $60-80 \%$. Patients were allowed to rest for $30 \mathrm{~min}$ before the measurements were made, and the test was performed with patients in the upright sitting position. A saccharin tablet ( $1 \mathrm{~mm}$ in diameter) was placed in the anterior part of the lower concha. The time from the placement of the saccharin tablet to the patient reporting the sweet taste of sugar was defined as the saccharine clearance time.

\section{Statistical analysis}

All statistical tests were performed using the Statistical Package for the Social Sciences (version 25; IBM Corp., Armonk, NY, USA). The Shapiro-Wilk test was used to determine the normality of the data distribution. $P$ values $<0.05$ were considered to indicate statistical significance. The chi-square test was used to compare nominal variables between groups, and independent samples $t$ tests or the Mann-Whitney $U$ test was used to compare numerical variables between groups. Pearson or Spearman correlation analysis was used to test for relationships between numerical variables.

\section{Results}

The study included 80 participants (40 COVID-19-positive patients and 40 healthy controls). The study and control groups were not significantly different in terms of age $(42.25 \pm 17.24$ vs. $49.08 \pm 13.80$ years, respectively; $t=1.954, p=0.054)$ or the distribution of males $(67.5 \%$, $n=27$ vs. $60.0 \%, n=24$, respectively) and females (32.5\%, $n=13$ vs. $40.0 \%, n=16$, respectively; chi-square $=0.487$, $p=0.485$ ).

The mean SNOT-22 score of the study group was $16.63 \pm 15.29$. The median (min-max) SNOT-22 scores of males (9.00 [2-44]) and females (20.00 [2-41]) were not significantly different $(Z=0.652, p=0.514)$.

The mucociliary clearance time was significantly different between the study and control groups, but not significantly different between males and females (Table 1).

Furthermore, mucociliary clearance time was significantly correlated with age (Spearman $r=0.696, p<0.001$ ),
Table 1 Comparison of the mean mucociliary clearance between different groups

\begin{tabular}{llllllll}
\hline & \multicolumn{2}{l}{ Control group } & & & \multicolumn{2}{l}{ Study group } & \\
\cline { 2 - 3 } & $\mathrm{N}$ & Mean & $\mathrm{SD}$ & & $\mathrm{n}$ & Mean & SD \\
\hline Male & 24 & 10.08 & 3.64 & 27 & 15.89 & 5.95 \\
Female & 16 & 8.63 & 3.73 & & 13 & 14.77 & 4.81 \\
Total & 40 & 9.50 & 3.70 & & 40 & 15.53 & 5.57 \\
\hline
\end{tabular}

${ }^{\mathrm{a}}$ Mucociliary clearance between males and females in the control group: $t=1.227, p=0.227$

${ }^{\mathrm{b}}$ Mucociliary clearance between males and females in the study group: $t=0.590, p=0.558$

${ }^{c}$ Difference in mucociliary clearance between the study and control groups: $Z=4.675, p<0.001$ ) 
Fig. 2 Correlations between age and mucociliary clearance time according to group

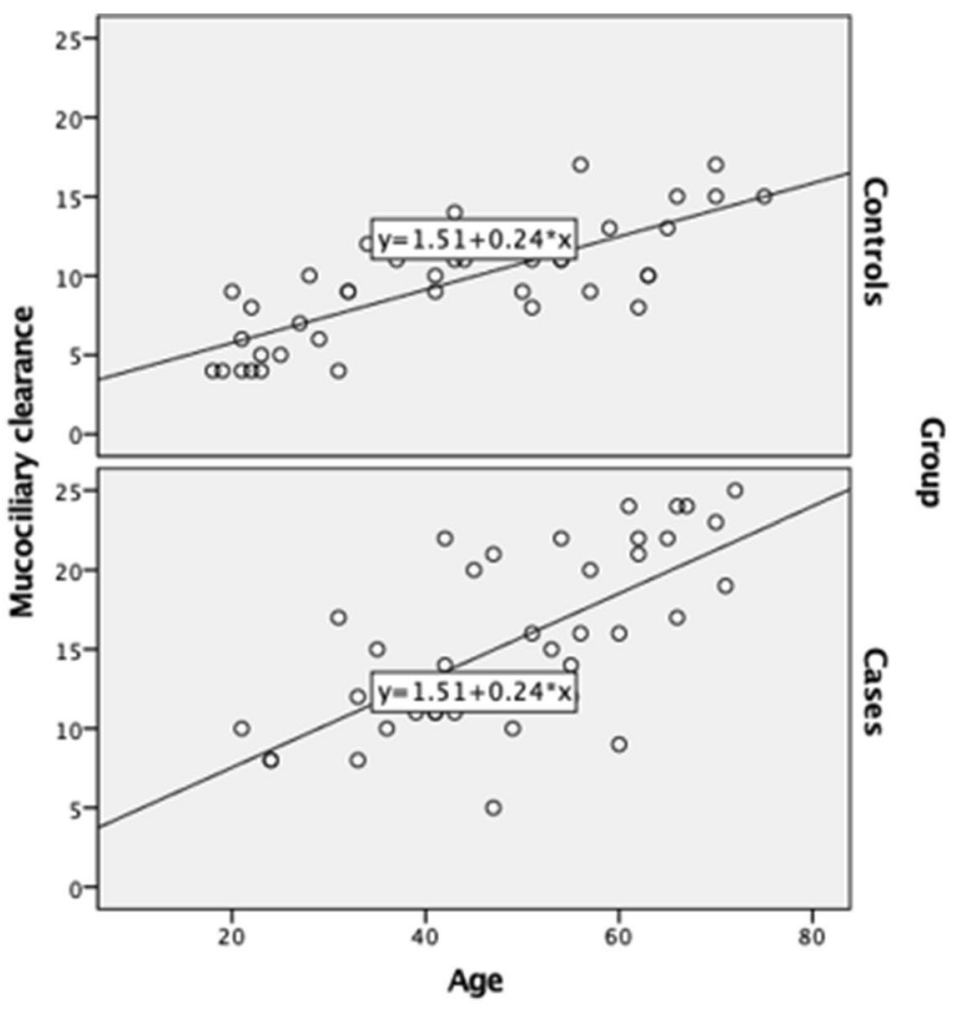

Cases $R^{2}$ Linear $=0.463$ Controls $R^{2}$ Linear $=0.610$ whereas the SNOT-22 score was not correlated with age in the study group (Spearman $r=0.160, p=0.324$ ).

The relationship between age and mucociliary function was significant in the study $(r=0.680, p<0.001)$ and control ( $r=0.781, p<0.001)$ groups (Fig. 2).

\section{Discussion}

We found that the mucociliary clearance time was significantly different between patients with COVID-19 and healthy controls. However, the mucociliary clearance time was not significantly different between males and females. Moreover, we found a significant, positive correlation between mucociliary clearance time and age.

A recent literature review found that $87 \%$ of patients with COVID-19 presented between the ages of 30 and 79 years [12]. Although outpatients may be somewhat younger, a meta-analysis of 1576 patients found that the median age was 49.6 years [13]. Thus, the age of our study participants is consistent with that in previous studies.

COVID-19 does not differentially affect males and females [13]; however, the proportions of hospitalisation, complications and mortality are thought to be higher in males. Although there are plausible findings [14], obesity, age and male sex have been shown to be independently associated with higher mortality and worse outcomes [15]. Because our study participants were hospitalised patients, the predominance of males is consistent with previous reports.

Previous studies of the effects of age and sex on mucociliary clearance have yielded conflicting findings. Although some authors have concluded that age and sex have no influence on mucociliary clearance $[16,17]$, the mucous membrane of the nasal cavity undergoes specific age-related changes that may increase mucociliary clearance time [18]. Our findings support age-related physiological changes in mucociliary function.

Various methods have been used to assess mucociliary clearance, including radiography using radiopaque materials (Teflon mixed with bismuth trioxide), gamma scintigraphy using radioactive materials (Tc99 or Indium111), the dye method and saccharin test [19-21]. Gamma scintigraphy is accepted as the most effective test but it is requires expensive equipments [19]. By contrast, the saccharin test is widely used because it is inexpensive, easy to perform and provides reliable results [19]. Our observation that the respiratory symptoms of COVID-19 were extremely heterogeneous is consistent with previous clinical and research findings.

The characteristic clinical symptoms of COVID-19 disease include fever, dry cough, tiredness, sputum, shortness of breath, sore throat and headache. However, physicians should consider COVID-19 infection as a differential diagnosis in patients with no common symptoms of the disease, but who present with a sudden and serious loss of smell [22]. 
Although the physiology of the sense of smell is not fully understood, infections of the neuronal cells located in the olfactory epithelium of the nose are known to cause anosmia. Moreover, post-viral upper respiratory tract infections cause inflammatory changes that can impair the sense of smell [23]. Although it is well known that viral infections affect the sense of smell, the underlying pathophysiology is not fully understood [3, 22]. Viruses that cause changes in smell perception include rhinovirus, parainfluenza virus, Epstein-Barr virus and some coronaviruses. Furthermore, the COVID-19 infection may also cause inflammation in non-neuronal cells, leading to anosmia and changes in smell perception [3, 24].

The large epithelial surface of the respiratory tract between the nose and alveoli is exposed to viral and bacterial pathogens, particles and gaseous substances with potentially harmful effects daily. Under normal conditions, mucociliary clearance is the primary defence mechanism of the respiratory system [25]. Healthy airway surfaces are lined with ciliary epithelial cells. Effective mucociliary clearance requires coordinated interaction of the mucus and periciliary layers covering the respiratory surface [26].

NMCT may be affected by several factors, including allergic rhinitis, sinusitis, nasal polyposis, trauma, sinonasal surgery, toxins, drugs, environmental heat, smoking, pressure and $\mathrm{pH}$. Furthermore, viral infections have been shown to affect NMCT. In 2017, Chinnapaiyan et al. [27] reported that HIV infection suppressed tracheobronchial mucociliary clearance and predisposed patients to recurrent lung infections, pneumonia and chronic bronchitis. Similarly, Durmuş et al. [28] found that the NMCT was prolonged in adult patients with Crimean-Congo haemorrhagic fever compared with healthy individuals in the control group.

Similarly, paranasal sinus inflammation due to a common cold can cause abnormal nasal airflow and mucociliary clearance times in allergic individuals [29]. Moreover, the NMCT is prolonged in patients with cystic fibrosis. Scambler et al. [30] investigated the overlap in the pathophysiologies of cystic fibrosis and COVID-19 infection. Furthermore, a previous study found that patients with cystic fibrosis and those with COVID-19 exhibited cytokine dysfunction and hyperinflammation [31].

Our findings should be interpreted in light of some limitations. First, only the study group was asked to complete the SNOT-22 questionnaire. Although the sample size was sufficient to answer our research question with a medium-tolarge effect size, a larger sample would have provided more precise findings. Finally, we did not investigate the nasal mucosal pathophysiology. The strength of our study is that despite being conducted during an outbreak, all measurements were performed by the same researcher to prevent bias.

\section{Conclusions}

Previous reports that both viral infections and cystic fibrosis can change mucociliary clearance times prompted us to investigate whether COVID-19 alters the NMCT or nasal physiology. Our findings revealed that the NMCT was prolonged in patients with COVID-19 compared with healthy controls, suggesting that the loss of smell and taste are crucial symptoms that should not be overlooked in patients suspected of having COVID-19 disease. Despite some limitations, we believe our study makes a valuable contribution as a preliminary study and warrants further multicentre investigation as the pandemic progresses. A better understanding of the changes to nasal physiology caused by SARS-CoV-2 may contribute to the development of future treatments and improve understanding of the pathogenesis of COVID-19 infection.

Funding This study was not funded by any source.

\section{Compliance with ethical standards}

Conflict of interest There were no conflicts of interest for any author. All authors contributed to and approved this manuscript.

\section{References}

1. Lescure FX, Bouadma L, Nguyen D et al (2020) Clinical and virological data of the first cases of COVID-19 in Europe: a case series. Lancet Infect Dis 20(6):697-706. https://doi.org/10.1016/ S1473-3099(20)30200-0

2. WHO (2020) Rolling updates on coronavirus disease (COVID19). WHO, Geneva

3. Yan CH, Faraji F, Prajapati DP, Boone CE, DeConde AS (2020) Association of chemosensory dysfunction and COVID-19 in patients presenting with influenza-like symptoms. Int Forum Allergy Rhinol 10(7):806-813. https://doi.org/10.1002/alr.22579

4. Duran M, Ulkü CH (2014) Effect of radiofrequency thermal ablation treatment on nasal mucociliary clearance in patients with isolated inferior turbinate hypertrophy. Kulak Burun Bogaz Ihtis Derg 24(4):185-189. https://doi.org/10.5606/kbbihtisas .2014 .58998

5. Kesimci E, Bercin S, Kutluhan A, Ural A, Yamanturk B, Kanbak $\mathrm{O}$ (2008) Volatile anesthetics and mucociliary clearance. Minerva Anestesiol 74(4):107-111

6. Jones N (2001) The nose and paranasal sinuses physiology and anatomy. Adv Drug Deliv Rev 51(1-3):5-19. https://doi. org/10.1016/s0169-409x(01)00172-7

7. Faul F, Erdfelder E, Lang AG, Buchner A (2007) G*Power 3: a flexible statistical power analysis program for the social, behavioral, and biomedical sciences. Behav Res Methods 39(2):175-191. https://doi.org/10.3758/bf03193146

8. Hanc1 D, Altun H, Sahin E, Altıntoprak N, Cingi C (2015) Turkish translation, cross-cultural adaptation and validation of the SinoNasal Outcome Test (SNOT)-22. ENT Updat 5(2):51-57. https://doi. org/10.2399/jmu.2015002001 
9. Asai K, Haruna S, Otori N, Yanagi K, Fukami M, Moriyama H (2000) Saccharin test of maxillary sinus mucociliary function after endoscopic sinus surgery. Laryngoscope 110(1):117-122. https://doi.org/10.1097/00005537-200001000-00021

10. Greenstone M, Cole PJ (1985) Ciliary function in health and disease. Br J Dis Chest 79(1):9-26. https://doi.org/10.1016/00070971(85)90003-8

11. Hopkins C, Gillett S, Slack R, Lund VJ, Browne JP (2009) Psychometric validity of the 22-item sinonasal outcome test. Clin Otolaryngol 34(5):447-454. https://doi.org/10.111 1/j.1749-4486.2009.01995.x

12. Wang L, Wang Y, Ye D, Liu Q (2020) Review of the 2019 novel coronavirus (SARS-CoV-2) based on current evidence. Int J Antimicrob Agents 55(6):105948. https://doi.org/10.1016/j.ijantimica g.2020.105948

13. Yang J, Zheng Y, Gou X et al (2020) Prevalence of comorbidities and its effects in patients infected with SARS-CoV-2: a systematic review and meta-analysis. Int J Infect Dis 94:91-95. https://doi. org/10.1016/j.ijid.2020.03.017

14. Palaiodimos L, Kokkinidis DG, Li W et al (2020) Severe obesity, increasing age and male sex are independently associated with worse in-hospital outcomes, and higher in-hospital mortality, in a cohort of patients with COVID-19 in the Bronx. New York Metab 108:154262. https://doi.org/10.1016/j.metabol.2020.154262

15. Fu L, Fei J, Xiang HX et al (2020) Analysis of death risk factors among 200 COVID-19 patients in Wuhan, China: a hospital-based case-cohort study. Lancet Respir Med. https://doi.org/10.2139/ ssrn. 3551430

16. Kao CH, Jiang RS, Wang SJ, Yeh SH (1994) Influence of age, gender, and ethnicity on nasal mucociliary clearance function. Clin Nucl Med 19(9):813-816. https://doi.org/10.1097/00003072199409000-00015

17. Mortensen J, Lange P, Nyboe J, Groth S (1994) Lung mucociliary clearance. Eur J Nucl Med 21(9):953-961. https://doi. org/10.1007/BF00238119

18. Petrov VV (2016) Age features of mucociliary system the mucous membrane of the nasal cavity of the human. Adv Gerontol 29(3):507-510

19. Lale AM, Mason JD, Jones NS (1998) Mucociliary transport and its assessment: a review. Clin Otolaryngol Allied Sci 23(5):388396. https://doi.org/10.1046/j.1365-2273.1998.00173.x

20. De España R, Franch M, García A, Pavía J (1986) Measurement of nasal mucociliary transport rate in normal man. Rhinology 24(4):241-247

21. Yergin BM, Saketkhoo K, Michaelson ED, Serafini SM, Kovitz K, Sackner MA (1978) A roentgenographic method for measuring nasal mucous velocity. J Appl Physiol Respir Environ Exerc Physiol 44(6):964-968. https://doi.org/10.1152/jappl.1978.44.6.964

22. Izquierdo-Dominguez A, Rojas-Lechuga MJ, Mullol J, Alobid I (2020) Olfactory dysfunction in the COVID-19 outbreak. J Investig Allergol Clin Immunol. https://doi.org/10.18176/jiaci.0567

23. Jaume F, Quintó L, Alobid I, Mullol J (2018) Overuse of diagnostic tools and medications in acute rhinosinusitis in Spain: a population-based study (the PROSINUS study). BMJ Open 8(1):e018788. https://doi.org/10.1136/bmjopen-2017-018788

24. Brann DH, Tsukahara T, Weinreb C, Lipovsek M, Van den Berge $\mathrm{K}$, Gong B et al (2020) Non-neuronal expression of SARS-CoV-2 entry genes in the olfactory system suggests mechanisms underlying COVID-19-associated anosmia. Sci Adv 5801:1-29. https:// doi.org/10.1126/sciadv.abc5801

25. Stannard W, O'Callaghan C (2006) Ciliary function and the role of cilia in clearance. J Aerosol Med 19(1):110-115. https://doi. org/10.1089/jam.2006.19.110

26. Bustamante-Marin XM, Ostrowski LE (2017) Cilia and mucociliary clearance. Cold Spring Harb Perspect Biol 9(4):a028241. https ://doi.org/10.1101/cshperspect.a028241

27. Chinnapaiyan S, Parira T, Dutta R et al (2017) HIV infects bronchial epithelium and suppresses components of the mucociliary clearance apparatus. PLoS ONE 12(1):e0169161. https://doi. org/10.1371/journal.pone.0169161

28. Durmuş K, Engin A, Karataş TD, Gözel MG, Altuntas EE (2017) Determination of nasal mucociliary clearance time and nasal symptom in patients with Crimean-Congo hemorrhagic fever. J Med Virol 89(6):960-965. https://doi.org/10.1002/jmv.24727

29. Alho OP (2004) Nasal airflow, mucociliary clearance, and sinus functioning during viral colds: effects of allergic rhinitis and susceptibility to recurrent sinusitis. Am J Rhinol 18(6):349-355

30. Scambler T, Jarosz-Griffiths HH, Lara-Reyna S et al (2019) ENaC-mediated sodium influx exacerbates NLRP3-dependent inflammation in cystic fibrosis. Elife 8:e49248. https://doi. org/10.7554/eLife.49248

31. Lee Y, Min P, Lee S, Kim SW (2020) Prevalence and duration of acute loss of smell or taste in COVID-19 patients. J Korean Med Sci 35(18):e174. https://doi.org/10.3346/jkms.2020.35.e174

Publisher's Note Springer Nature remains neutral with regard to jurisdictional claims in published maps and institutional affiliations. 